\title{
Does Emotional Distress Tolerance Predict Fear Responding in a Heights-Fearful Sample?
}

Amber Lynn Billingsley

West Virginia University, alb0061@mix.wvu.edu

Follow this and additional works at: https://researchrepository.wvu.edu/etd

Part of the Clinical Psychology Commons

\section{Recommended Citation}

Billingsley, Amber Lynn, "Does Emotional Distress Tolerance Predict Fear Responding in a Heights-Fearful Sample?" (2019). Graduate Theses, Dissertations, and Problem Reports. 7449.

https://researchrepository.wvu.edu/etd/7449

This Thesis is protected by copyright and/or related rights. It has been brought to you by the The Research Repository @ WVU with permission from the rights-holder(s). You are free to use this Thesis in any way that is permitted by the copyright and related rights legislation that applies to your use. For other uses you must obtain permission from the rights-holder(s) directly, unless additional rights are indicated by a Creative Commons license in the record and/ or on the work itself. This Thesis has been accepted for inclusion in WVU Graduate Theses, Dissertations, and Problem Reports collection by an authorized administrator of The Research Repository @ WVU. For more information, please contact researchrepository@mail.wvu.edu. 
Does Emotional Distress Tolerance Predict Fear Responding in a Heights-Fearful Sample?

Amber L. Billingsley, B.A.

Thesis defense submitted to

Eberly College of Arts and Sciences at West Virginia University in partial fulfillment of the requirements for the degree of

Master of Science in Psychology

Shari Steinman, Ph.D. (Chair)

Natalie Shook, Ph.D.

Amy Gentzler, Ph.D.

Department of Psychology

Morgantown, West Virginia

2019

Keywords: Emotional Distress Tolerance, Fear Responding, Fear of Heights, Avoidance

Copyright 2019 Amber Billingsley 


\begin{abstract}
Does Emotional Distress Tolerance Predict Fear Responding in a Heights-Fearful Sample?
\end{abstract}

Amber L. Billingsley

Emotional distress tolerance — or the ability to withstand negative emotional states—is considered a transdiagnostic risk factor for psychopathology. Although it is theorized to play an important role in anxiety, research aiming to delineate the relationship between anxiety and emotional distress tolerance is lacking. The current study tested whether an individual's selfreported emotional distress tolerance predicted avoidance in the presence of feared stimuli using a heights-fearful sample. Moreover, the study tested whether emotional distress tolerance predicted other relevant in-the-moment fear responses, such as peak anxiety, anxious cognitions, and bodily sensations while in a heights scenario. Participants $(N=85)$ completed a series of questionnaires assessing fear of heights, general negative affect, anxious cognitions, and bodily sensations, as well as two behavioral avoidance tasks (BATs) related to heights, one occurring in vivo and one occurring in virtual reality (VR). Results demonstrated that emotional distress tolerance did not predict avoidance on either of the two BATs. Emotional distress tolerance also did not predict other in-the-moment fear responses in either of the BATs except for peak anxiety in the in vivo task. Post-hoc analyses revealed that emotional distress tolerance did predict selfreported avoidance of heights above and beyond fear of heights and general negative affect. Taken together, results suggest that one's perception of their ability to tolerate emotional distress predicts their perception of their avoidance of heights, but not their actual avoidance of heights or reactions to heights (with the exception of peak anxiety in vivo). Given these findings, selfreported emotional distress tolerance may not adequately capture how individuals react in distressing situations. Future research should clarify in what ways, if any, emotional distress tolerance affects behavior. 


\section{Acknowledgements}

First, I would like to thank my adviser, Dr. Shari Steinman, for her patience, kindness, and words of encouragement throughout this process. I sincerely appreciate everything she did to help me develop and execute this challenging project. I am also very grateful to my committee members, Dr. Natalie Shook and Dr. Amy Gentzler, for their invaluable feedback on my project and for helping me make this into the best study it could be. I would like to thank my student colleagues and friends in the Department of Psychology who provided feedback on drafts and worked alongside me as I wrote. Lastly, I would like to thank my husband and our (furry) children for always being there for me throughout this long process and for keeping me company as I worked, providing lots of love and support along the way. 


\section{Table of Contents}

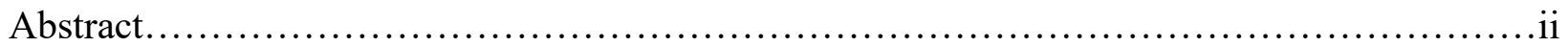

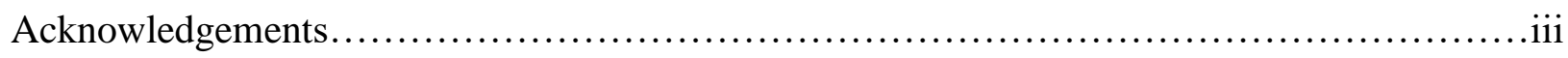

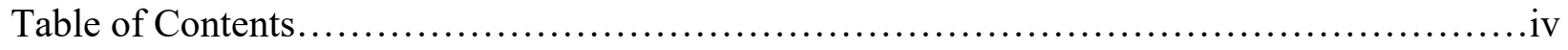

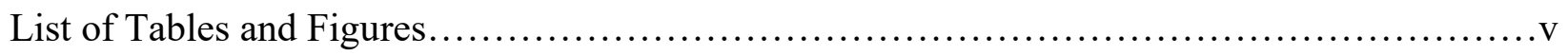

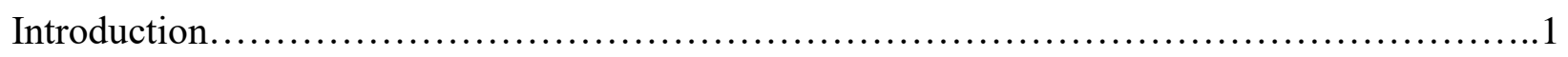

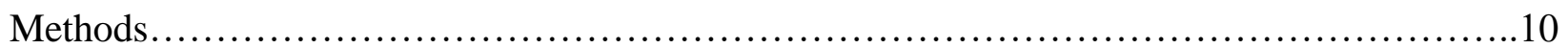

Participants............................................................ 10

Measures.................................................................. 11

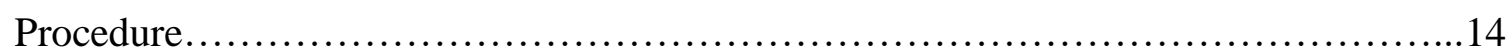

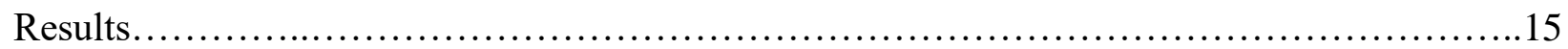

Descriptive statistics.................................................... 16

Group differences....................................................... 17

Correlations.............................................................. 17

Primary analysis........................................................... 18

Secondary analyses..................................................... 19

Post-hoc analyses......................................................20

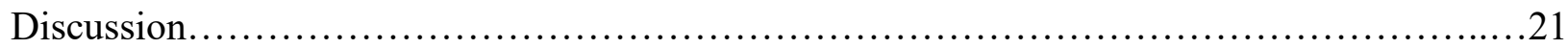

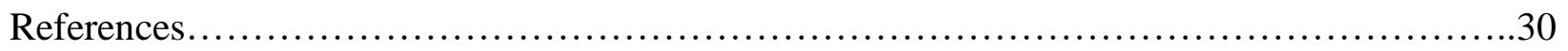

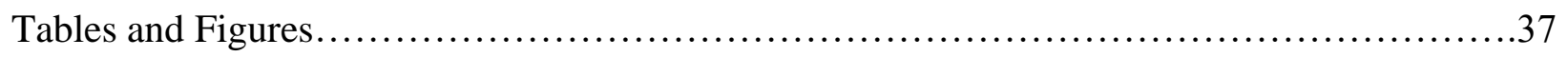




\section{List of Tables and Figures}

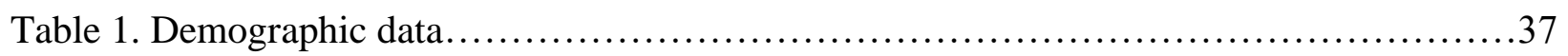

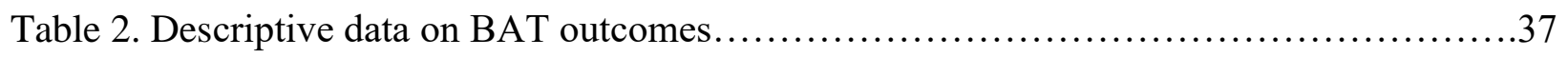

Table 3. Bivariate correlations between predictor and dependent variables...................38

Table 4. Hierarchical regressions of primary analyses using DTS to predict avoidance above AQ-

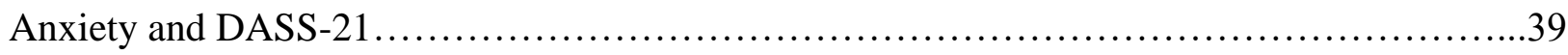

Table 5. Hierarchical regressions of secondary analysis using DTS to predict peak anxiety above

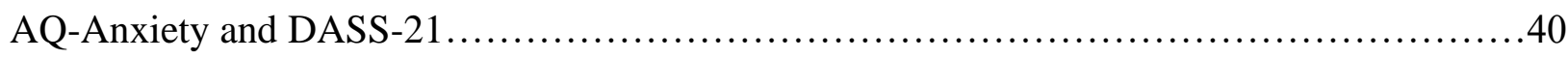

Table 6. Hierarchical regressions of secondary analysis using DTS to predict ACQ above AQ-

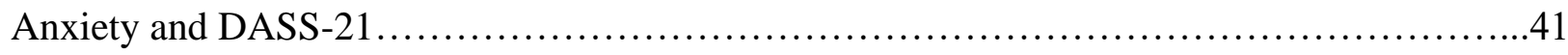

Table 7. Hierarchical regressions of secondary analysis using DTS to predict BSQ above AQ-

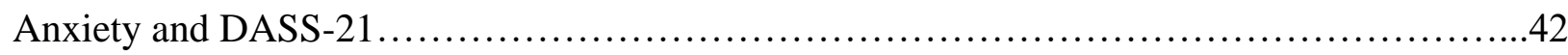

Table 8. Hierarchical regression of post-hoc analysis using DTS to predict self-reported

avoidance of heights (AQ-Avoidance) above AQ-Anxiety and DASS-21 ...................43

Figure 1. Photographs of in vivo BAT..............................................44

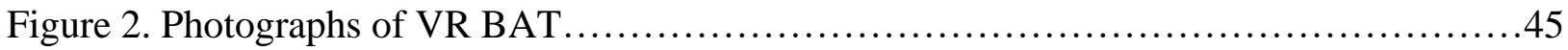


Does Emotional Distress Tolerance Predict Fear Responding in a Heights-Fearful Sample?

Despite its potential importance to psychopathology, emotional distress tolerance (EDT), or the ability to handle aversive emotional states, is understudied within the field of anxiety. Specifically, even though EDT is theorized to play an important role in anxiety and the avoidance behaviors that maintain anxiety (Keough, Riccardi, Timpano, Mitchell, \& Schmidt, 2010), little work has been done to test the relationship of EDT to anxiety responses.

Past research on EDT and obsessive-compulsive symptoms found that EDT was a significant predictor of whether or not someone engaged in compulsion-like behavior (Cougle, Timpano, Fitch, \& Hawkins, 2011), though researchers did not assess whether EDT predicted this behavior beyond that of other relevant symptoms. Further, it has been found that EDT uniquely predicts self-reported dysregulated behaviors above and beyond disorder-relevant symptoms and negative affect in eating disorders (e.g. Anestis, Selby, Fink, \& Joiner, 2007). Given findings from these studies, it may be the case that EDT will also predict actual avoidance behaviors in anxiety, even after controlling for anxiety severity and general negative affect. Since avoidance and anxiety are often concordant and mutually influential, it is necessary to establish the role of EDT in avoidance behaviors.

To the author's knowledge, there is no existing literature on the relationship between EDT and in-the-moment responding when phobic individuals are asked to approach feared stimuli. Thus, this study primarily tested whether individual differences in EDT levels predicted real-life behavioral avoidance on heights in a heights-fearful sample above and beyond fear of heights and general negative affect. As a secondary analysis, we tested whether EDT predicted other relevant anxiety responses, such as state anxiety, anxious cognitions, and bodily sensations 
on heights. Finally, post-hoc analyses were conducted to determine the relationship between EDT and self-reported avoidance of heights.

\section{Distress tolerance definition and measurement}

EDT is described as one's ability to withstand and handle aversive emotional states, and is one of five facets of the overall global distress tolerance ${ }^{1}$ construct, which includes one's ability to handle both psychological as well as physical distress (Leyro, Zvolensky, \& Bernstein, 2010). In addition to EDT, the global distress tolerance construct includes intolerance of uncertainty, which is the tendency to react negatively to uncertain situations; tolerance of ambiguity, which is the way in which an individual reacts to vague or ambiguous situations in the moment; tolerance of frustration, which is an individual's capacity to withstand frustration or aggravation; and tolerance of physical discomfort (also referred to as discomfort intolerance), which reflects the extent to which individuals can tolerate uncomfortable bodily sensations.

A meta-analysis of the distress tolerance literature (Leyro et al., 2010) identified two general conceptualizations of distress tolerance: (1) an individual's perceived capacity to handle distress, and (2) the behavioral act of actually doing so. These two conceptualizations are reflected in the ways in which distress tolerance is broadly assessed, which involves both selfreport measures as well as behavioral/biobehavioral measures (Zvolensky, Vujanovic, Bernstein, \& Leyro, 2010). Although self-report measures exist for all five dimensions, researchers have had difficulty creating reliable behavioral measures that specifically assess EDT (Veilleux, Pollert, Zielinski, Shaver, \& Hill, 2019), which may be the most relevant facet of distress tolerance to anxiety.

Current behavioral measures of distress tolerance include the cold-pressor task, the breath-holding task, the mirror-tracing task, and the Paced Auditory Serial Addition Task

\footnotetext{
${ }^{1}$ The tolerance of negative emotions will simply be referred to as emotional distress tolerance whereas the global distress tolerance concept or research integrating multiple facets of distress tolerance will simply be referred to as "distress tolerance."
} 
(PASAT-C; Brown, Lejuez, Kahler, \& Strong, 2002; Compton, Charuvastram \& Ling, 2001; Strong et al., 2003; Zvolensky, Feldner, Eifert, \& Brown, 2003). However, these tasks only measure frustration tolerance and discomfort intolerance, rather than EDT (Glassman et al., 2016). In the cold-pressor task, an individual is asked to keep their hand submerged in ice water for as long as possible whereas in the breath-holding task, an individual is asked to hold their breath for as long as possible. Both of these behavioral tasks measure discomfort intolerance. The mirror-tracing task, in which an individual uses a mirrored computer cursor to trace objects on a screen, and the PASAT-C, in which an individual is asked to sequentially add numbers, are both behavioral measures of frustration tolerance. Importantly, a review of the existing literature has shown that self-report measures of EDT and biobehavioral measures of other dimensions of distress tolerance are often not significantly related to one another, indicating that current measurement of EDT is limited to self-report (McHugh et al., 2011). Although the global distress tolerance construct encompasses a range of literature and concepts, EDT is of particular interest because of its potential to account for unique variance in behavioral avoidance in psychopathology (Leyro et al., 2010).

\section{Distress tolerance and avoidance}

Theoretical perspectives on distress tolerance and avoidance (Leyro et al., 2010) posit that individuals lower in distress tolerance are more likely to use maladaptive coping techniques in the presence of distress. Specifically, individuals with poor EDT may be prone to avoid negative emotional states or future situations in which aversive emotions may arise, negatively reinforcing their anxiety. On the contrary, individuals with high levels of EDT may be more likely to approach situations in which they may experience a negative emotion, which should 
lead to more adaptive coping strategies. Previous research suggests that males report higher EDT than females (Simons \& Gaher, 2005), though it is unclear what drives this gender difference.

EDT predicts avoidance behaviors across a range of psychopathology. For instance, individuals with lower EDT are more likely to abuse substances in an effort to avoid negative emotional states than are those with higher levels of EDT (Leyro, Bernstein, Vujanovic, McLeish, \& Zvolensky, 2011). Additionally, EDT has been shown to be predictive of cigarette dependence, nicotine craving, and negative reinforcement of smoking behaviors (i.e. smoking to reduce negative affect) significantly more so than an individual's level of anxious and depressive symptoms (Trujillo et al., 2017). Furthermore, low levels of EDT may lead to an increase in smoking behaviors after overnight abstinence from tobacco (Perkins, Karelitz, Giedgowd, Conklin, \& Sayette, 2010), which is in line with previous research that found that lower distress tolerance as measured on behavioral tasks predicts drop-out from smoking cessation treatment and relapse (Abrantes et al., 2008; Brown et al., 2009).

In addition to substance abuse behaviors, low EDT is implicated in dysregulated eating. In a non-clinical sample, lower EDT scores were correlated with higher scores on scales of emotional eating, or using food to cope with negative emotions (Kozak \& Fought, 2011). Importantly, EDT accounts for much of the variance in the behaviors that make up bulimia (e.g. binging, purging) significantly above and beyond anxiety and depressive symptoms, indicating that the predictive ability of EDT is not simply due to negative affect (Anestis et al., 2007).

Finally, in addition to predicting overt avoidance behaviors such as substance abuse and dysregulated eating, EDT has been shown to predict subtler avoidance behaviors, such as cognitive avoidance (Huang et al., 2009). More specifically, individuals with poor EDT were more likely to utilize cognitive avoidance strategies such as excessive worrying in an effort to 
avoid accessing fear-relevant information in long-term memory, even when controlling for general negative affect including both anxiety and depressive symptoms (Huang et al., 2009).

A growing number of studies have assessed the role that EDT plays in hoarding disorder. Specifically, research has found that EDT is negatively associated with hoarding behaviors (Timpano, Buckner, Richey, Murphy, and Schmidt, 2009). This suggests that EDT may play a role in maintaining obsessive-compulsive and related disorders (OCRDs). Additionally, Williams (2012) found that compulsive buying was uniquely related to a measure of tolerance of negative emotions, even after controlling for general psychopathology, impulsivity, and experiential avoidance (Williams, 2012). Together, these findings suggest that EDT plays a unique role in hoarding behaviors.

Additionally, studies suggest that EDT plays a role in obsessive compulsive disorder (OCD). EDT uniquely predicts OCD symptoms beyond general negative affect (Keough et al., 2010) and lower levels of EDT are predictive of obsessions after accounting for related constructs such as anxiety sensitivity, depression, and obsessive beliefs (Cougle et al., 2011). Importantly, the unique predictive abilities of EDT on obsessive compulsive-like symptoms have been observed through other methods of assessment in addition to self-report. In particular, a study by Cougle et al. (2011) included a neutralization task in which unselected college students were asked to rate their anxiety as they wrote and thought about distressing scenarios, such as a friend getting into a car accident, and were instructed that they were free to do whatever they liked with the paper on which they had written. Importantly, results revealed that poor EDT predicted compulsion-like neutralization behaviors, including destroying or altering sentences to be more favorable, turning over the paper, using religious strategies, or completing superstitious acts. These results indicate that individuals who have lower levels of EDT may be more likely to 
utilize maladaptive coping strategies when in the presence of distressing stimuli (Cougle et al., 2011). Although this study assessed the relationship between compulsive-like behaviors and EDT, an unselected sample was used (as opposed to a sample with high obsessive-compulsive symptoms), other in-the-moment anxiety responses were not assessed, and participants were split into groups depending on whether they neutralized or not, only permitting researchers to look at group differences (vs. individual differences). Further, this study did not assess whether EDT predicted behavior beyond other related variables (e.g. OCD symptoms).

Although the literature regarding the relationship between EDT and the psychopathology discussed above is growing, the research pertaining to EDT and anxiety disorders remains limited. Besides the study by Cougle and colleagues (2011) discussed above, few studies have examined the direct effects of EDT on anxiety, with most focusing on the relationship between EDT and processes related to anxiety symptomatology instead of in-the-moment fear responding. Anxiety sensitivity, or the fear of anxiety-related sensations, has been shown to have an inverse relationship with EDT in a number of different studies, indicating that individuals with poorer EDT levels also tend to be more sensitive to and fearful of anxiety-related sensations (Anestis et al., 2007; Bernstein, Zvolensky, Vujanovic, \& Moos, 2009; Timpano et al., 2009; Zvolensky, Marshall, Johnson, Hogan, Bernstein, \& Bonn-Miller, 2009). Additionally, EDT is negatively correlated with multiple self-report anxiety symptom questionnaires, such as panic, social anxiety, obsessive-compulsive, and worry (Keough et al., 2010). Importantly, EDT was predictive of these self-report anxiety symptoms after controlling for general negative affect.

Given the association between EDT and anxiety symptomatology, it is hypothesized that EDT will be implicated in reactions to feared stimuli in samples with high levels of anxiety, such as state anxiety, behavioral avoidance, negative cognitions, and bodily sensations. To the 
author's knowledge, no studies have yet to examine the predictive abilities of EDT on phobic symptom dimensions or on a variety of in-the-moment anxiety responses, such as overt and clearly defined behavioral avoidance. Thus, we are limited in what we can infer about the relationship between EDT and state anxiety responses, highlighting the need for research assessing the relationship between the two constructs.

\section{Conceptualizations of anxiety and avoidance}

Perhaps one of the earliest and most influential conceptualizations of anxiety and avoidance was Mowrer's two factor theory (Mowrer, 1953). According to Mowrer (1953), fear and anxiety function to motivate individuals to seek safety, which reinforces avoidance behaviors. Although Mowrer's original two factor theory is not fully accepted anymore due to the fact that avoidance can occur without regard to safety (Rachman, 1976; Krypotos, Effting, Kindt, \& Beckers, 2015), recent models retained Mowrer's notion that anxiety and avoidance are typically interrelated. Current cognitive-behavioral models posit that anxiety is maintained because avoiding distressing situations prompts an immediate reduction in fear; this reinforces perceptions that the situation was indeed dangerous, preventing new learning from occurring that the situation is actually benign or safe (Barlow, 2002). Thus, current conceptualizations also suggest that anxiety and avoidance behaviors may be highly related in many individuals experiencing anxiety.

Although avoidance and anxiety often relate, early research on the desynchrony between different measures of fear demonstrates how different modes of fear responding may not always correlate as would be expected (Lang, 1978; Lang, Cuthbert, \& Bradley, 1998; Rachman \& Hodgson, 1974; Hodgson \& Rachman, 1974). In fact, the diagnostic criteria for many anxiety disorders allows that distressing situations either be "actively avoided or endured with intense 
fear or anxiety" (DSM-5; American Psychiatric Association, 2013; emphasis added). Given this diagnostic clarification, it is clear that levels of avoidance across individuals with a certain anxiety disorder can drastically vary, even if these two constructs are typically correlated. There is little research on factors that may predict whether an individual with a diagnosed anxiety disorder avoids feared stimuli altogether or approaches it while experiencing intense anxiety.

In line with this diagnostic criterion (American Psychiatric Association, 2013), individuals do not always behave in a way that is consistent with what would be expected from their anxiety levels alone. Importantly, research suggests that factors besides anxiety level may affect behavior. For example, Steinman and Teachman (2011) found that interpretation biases relevant to heights predicts behavioral avoidance on heights above and beyond one's selfreported symptoms of acrophobia among individuals with varying levels of height fear. Further, Deacon and Olatunji (2007) found that disgust sensitivity was significantly associated with avoidant responding on a behavioral task even after controlling for anxiety, depression, gender, and level of contamination fear. Additionally, disgust was found to mediate the relationship between avoidance and high contamination fears on the behavioral task. Together, these results suggest that factors besides anxiety levels influence behavioral avoidance.

\section{Behavioral avoidance tasks (BATs)}

A common way to assess avoidance behaviors in the presence of feared stimuli is by using behavioral avoidance tasks (BATs). In a BAT, an individual is asked to get progressively closer to their feared stimuli or complete a series of increasingly difficult tasks until they no longer wish to continue. BATs are considered the most objective technique for assessing phobias (Lang and Lazovik, 1963) and are frequently used in both clinical and research settings. BATs are able to be tailored to individual patients and their unique symptoms and they are sensitive to 
symptom changes over time (Craske, Rapee, \& Barlow, 1988; McGlynn, 1988). Moreover, performance on BATs is related to treatment outcomes (e.g., Emmelkamp et al., 2002; Steketee, Chambless, Tran, Worden, \& Gillis, 1996), suggesting that even though BATs are artificial measurements of behavior, they are related to real-life behavior.

Being able to better predict response to BATs has a number of important clinical implications. Within a clinical setting, BATs are somewhat analogous to exposures used in Cognitive-Behavioral Therapy (CBT). Thus, individuals who do not exhibit very much approach behavior in a BAT may also be less likely to comply with homework demands, such as conducting exposures on their own or in session. Additionally, these individuals may be more likely to drop out of treatment because they are unable to fully habituate to their feared stimuli and fail to receive the full benefits of exposure treatments. In addition to clinical implications, BATs are important because they are similar to "real-life" situations and can give researchers valuable information about how an individual is likely to respond in a certain situation.

Similarly, responses to BATs are important because they allow researchers and clinicians to not rely as heavily on self-reports, which may be inaccurate given that one's perceived behavior does not necessarily reflect their actual behavior.

\section{Overview of study}

This study tested the extent to which individual differences in EDT predicted behavioral avoidance in a heights-fearful sample above and beyond other relevant variables, such as fear of heights and general negative affect. Behavioral avoidance was assessed using two behavioral avoidance tasks (BATs) in which heights-fearful individuals were asked to approach heights both in vivo and in a virtual reality environment. Secondary analyses tested the extent to which EDT predicted other relevant anxiety responses during the BATs, including state anxiety, anxious 
cognitions, and bodily sensations. Fear of heights (acrophobia) was specifically chosen due to its high prevalence (estimated prevalence rate of 3.1-5.3\%; LeBeau et al., 2010), similar prevalence rates between males and females (of individuals with acrophobia, $40 \%$ are male; LeBeau et al., 2010), the ease and simplicity of administering heights BATs, and the absence of literature on EDT and acrophobia.

It was hypothesized that EDT would predict avoidance behavior in a BAT above and beyond fear of heights and general negative affect, and would help elucidate why individuals who report similarly high anxiety ratings behave differently when actually in the presence of their feared stimuli. Further, it was hypothesized that EDT would predict other in-the-moment anxiety responses beyond fear of heights and general negative affect.

\section{Methods}

\section{Participants}

Participants consisted of college students and community members in the Morgantown, West Virginia area. Participants were recruited using multiple methods, including the Department of Psychology's preselection study at West Virginia University, flyers, advertisements in undergraduate classes, and university-wide email advertisements. In order to be eligible for the study, all interested participants were pre-screened with the Acrophobia Questionnaire-Anxiety subscale (AQ-Anxiety; see Measures), and those who scored 45.45 or higher were invited to participate (i.e. one standard below the mean of a heights-phobic sample, indicating high levels of heights fear; Cohen, 1972; Cohen, 1977). At the time of recruitment, participants were informed that the purpose of the study was to assess how individuals react on heights and, since this study was part of a larger parent study, to test an experimental intervention to reduce fear of heights. All measures utilized in the current study were obtained 
prior to the experimental intervention in the parent study. Subjects were incentivized by offering course credit for participation or cash at the rate of $\$ 10$ per hour, for a total of up to 5.5 course credits or $\$ 55$ for completing the full parent study.

A total of 98 participants who met the cut-off of 45.45 on the AQ-Anxiety at prescreening were enrolled in the study. As a check to ensure that participants who enrolled in the study were not misrepresenting their fear of heights, the AQ-Anxiety was re-administered to all participants at the beginning of the study (note: there was typically a delay of a week or more between pre-screening and study enrollment). To allow for normal fluctuations in symptoms and expected fluctuations in self-report, all participants must have scored at least a 38 or higher on the AQ-Anxiety at the beginning of the study (i.e. 1.5 standard deviations below the mean of a heights-phobic sample; Cohen, 1972; Cohen, 1977) in order to progress in the study. Twelve participants were excluded from analyses due to inconsistencies in their self-reported fear of heights and one participant was excluded from analyses for withdrawing from the study prior to completing the behavioral tasks, resulting in a total of 85 participants. Only data from these 85 participants is reported ${ }^{2}$.

The mean age of the sample was 22.69 years old $(S D=7.10$, range $=18-62)$. The sample was primarily female $(74.1 \%)$ and White $(67.1 \%)$. The majority of the sample consisted of undergraduate students $(77.6 \%)$. See table 1 for detailed demographic information on the gender and racial breakdown of the sample.

\section{Measures}

The following measures were administered throughout the course of this study. Selfreport measures were presented in a randomized order. The order of the BATs was counterbalanced.

\footnotetext{
${ }^{2}$ A power analysis was run to determine the minimum number of participants needed to detect a medium effect. It was determined that approximately 60 participants would be needed for this study. This effect size was based off of a study using a heights-fearful sample that utilized similar measures to this study, including a behavioral avoidance task (Steinman \& Teachman, 2011).
} 


\section{Emotional distress tolerance measure}

Distress Tolerance Scale. The Distress Tolerance Scale (DTS; Simons \& Gaher, 2005) is a 15-item self-report questionnaire that assesses perceived EDT. Items were rated on a Likert scale ranging from 1 ("strongly agree") to 5 ("strongly disagree"), with higher scores representing better ability to tolerate distress. Conceptually, the DTS includes four different types of questions that reflect four different components of EDT: (1) perceived tolerance, (2) appraisal, (3) absorption, and (4) regulation efforts. This measure shows good internal consistency and test-retest reliability as well as good convergent, divergent, and criterion validity (Simons \& Gaher, 2005).

\section{Height fear and negative affect measures}

Acrophobia Questionnaire. The Acrophobia Questionnaire (AQ; Cohen, 1977) is a 40item self-report questionnaire that assesses an individual's anxiety and avoidance related to heights. The AQ consists of two 20-item subscales assessing anxiety and avoidance. Items on the anxiety subscale were rated on a Likert-type scale from 0 ("Not at all anxious; calm and relaxed") to 6 ("Extremely anxious"). Items on the avoidance subscale were rated on a scale from 0 ("Would not avoid doing it") to 2 ("Would not do it under any circumstances"). The AQ has good psychometric properties (Baker, Cohen, \& Saunders, 1973; Bourque \& Ladouceur, 1980). The AQ-Anxiety was used to assess fear of heights and AQ-Avoidance was used to assessed perceived avoidance of heights scenarios.

Depression Anxiety Stress Scales. The Depression Anxiety Stress Scales (DASS-21; Lovibond \& Lovibond, 1995) is a 21-item widely used questionnaire that assesses general negative affect. Items were rated on a Likert scale ranging from 0 (“Did not apply to me at all”) to 4 ("Applied to me very much, or most of the time"). The DASS-21 has excellent psychometric 
properties (Antony, Bieling, Cox, Enns, \& Swinson, 1998). The DASS-21 was used to assess general negative affect.

\section{Measures assessing reactions on heights}

Behavioral Avoidance Task in Virtual Reality. Individuals wore a wireless virtual reality headset (Samsung Gear VR) and were immersed in a virtual environment consisting of a tower (Samsung \#BeFearless Fear of Heights - Cityscapes; see Figure 2). In each step of this BAT, participants were instructed to press a button that lifted them 20 meters. Participants were instructed that they could stop the task at any time and were informed that the task was not a test of courage or bravery. After each step, participants were asked for their current anxiety on a scale of 0 ("not at all anxious") to 100 ("the most anxious I could imagine"). This BAT had a total of 8 steps and went up as high as 160 meters. Participants received 1 point for each step they took out of a total of 8 points. Avoidance was operationalized as the total number of points gained (i.e. more points indicates less avoidance and more approach behavior). Peak anxiety was operationalized as the highest anxiety rating that the participant reported at any point during the task.

Behavioral Avoidance Task In Vivo. In the BAT in vivo, individuals were asked to ascend up to 4 flights of stairs and to look over the railing to the floor below at each landing (see Figure 1). Similar to the previous BAT, individuals were informed that they could refuse to complete any of the steps and that the task was not a test of courage. After each step of the BAT, individuals were asked to rate their anxiety on a scale of 0 ("not at all anxious") to 100 ("the most anxious I could imagine"). This BAT also had a total of 8 steps and participants were awarded 1 point for each step they completed. Ascending a flight of stairs and looking over the railing at each landing were considered separate steps and were awarded points separately. 
Avoidance was operationalized as the total number of points obtained (i.e. more points indicates less avoidance and more approach behavior). Peak anxiety was operationalized as the highest anxiety rating that the participant reported at any point during the task.

Agoraphobic Cognitions Questionnaire. The Agoraphobic Cognitions Questionnaire (Chambless, Caputo, Bright, \& Gallagher, 1984) is a 17-item self-report questionnaire that assesses cognitions about the negative outcomes of anxiety. Items were rated on a Likert scale from 0 ("Not at all") to 4 ("Extremely"). Higher scores indicate stronger thoughts about negative anxiety outcomes, including thoughts about throwing up, passing out, or acting foolish. The ACQ has been shown to have adequate psychometric properties (Chambless et al., 1984). This questionnaire was used to assess anxiety-related cognitions during both BATs.

Body Sensations Questionnaire. The Body Sensations Questionnaire (Chambless et al., 1984) is a 17-item self-report questionnaire that assesses bodily sensations that commonly occur during anxiety. Items were rated on a Likert scale from 0 ("None") to 4 ("Very severe"), with higher scores indicating more severely experienced adverse bodily sensations. The BSQ has adequate psychometric properties (Chambless et al., 1984). This questionnaire was used to assess anxiety-related bodily sensations during both BATs.

\section{Procedure}

Interested participants were administered the AQ-Anxiety online in order to determine their eligibility for the study. Those who scored above a 45.45 on this measure were invited to participate. The majority of participants ${ }^{3}$ were given the option to complete only the procedure as described in this study, or they could choose to complete the full parent study which included an experimental intervention designed to reduce fear of heights and took place over multiple sessions (note: the measures described in this study took place at the beginning of the first

\footnotetext{
${ }^{3}$ The first 7 participants were only given the option to complete the full parent study and the remainder of participants could choose to complete either the full parent study or only the measures described in this study. This change was made in order to speed up recruitment. Of those who were given the option, approximately $75 \%$ of participants opted to complete the full parent study.
} 
session of the parent study and were therefore unaffected by the experimental intervention). All participants provided informed consent and were given the opportunity to ask questions. This study was approved by West Virginia University’s Institutional Review Board (IRB).

Following informed consent, participants completed a series of computerized questionnaires on Qualtrics, including the AQ, DTS, and the DASS-21 (presented in random order). After completing the computerized self-reports, participants completed the two BATs (in a counterbalanced order). State anxiety was assessed on a 0-100 scale before beginning each BAT and upon completion of each step. Each BAT was followed by the ACQ and BSQ in random order, which assessed cognitions and bodily sensations experienced during the BAT. Prior to beginning the second BAT, state anxiety was assessed to determine if participants had residual anxiety from the first BAT that may affect their subsequent performance on the second BAT. If participants reported a state anxiety rating $>20$ points from their baseline anxiety level at the start of the first BAT, they were instructed to complete brief deep breathing exercises until their state anxiety rating was within 20 points of this baseline. Participants who opted to complete only this study were debriefed and compensated at this time. Participants who opted to complete the full parent study continued participating in other tasks and were debriefed and compensated following completion of the parent study.

\section{Results}

Prior to conducting statistical analyses, the data were checked for missingness and normality. Missingness was minimal (i.e. two participants were missing 1-2 items on the DTS and AQ) and was therefore corrected using mean imputation. All primary outcome measures were normally distributed with the exception of the ACQ in vivo, which was moderately positively skewed, and the DASS-21 total score, which was minimally positively skewed. These 
two variables were corrected using square root transformations. Notably, results described below did not differ using the original and transformed variables for ACQ in vivo and DASS-21. The variables for the number of BAT steps completed in vivo and VR were highly negatively skewed and minimally negatively skewed, respectively. However, due to the importance of the scaling on both BATs, these variables were not transformed. All other variables were normally distributed.

\section{Descriptive statistics}

On average, participants reported higher scores for peak anxiety ratings, anxious cognitions, and bodily sensations in the VR task compared to the in vivo task (see table 2). Participants had a mean AQ-Anxiety score of $62.05(S D=15.40$, range $=38-92)$, which is just above the average score of 60 for a phobic sample (Cohen, 1972; Cohen, 1977), and the mean score for the AQ-Avoidance subscale was $17.03(S D=5.92$, range $=5-30)$. The mean score for the DASS-21 total score was $19.47(S D=11.87$, range $=1-54)$, which is higher than that of a nonclinical sample (Antony et al., 1998; Sinclair et al., 2012). Lastly, the mean score on the DTS was $2.87(S D=.82$, range $=1.17-4.95)$, which is notably lower than that of the nonclinical, unselected college student sample from the original DTS publication $(M=3.43, S D=.76$; Simons \& Gaher, 2005).

The percentage of participants that completed all steps of the in vivo BAT was different from the percentage of participants that completed all steps of the VR BAT. In the in vivo BAT, $77.6 \%$ of participants completed all 8 steps of the task, whereas only $43.5 \%$ of participants completed all 8 steps of the VR task. On average, participants completed more steps of the in vivo BAT than the VR BAT (see table 2). 


\section{Group differences}

Since past research suggests that there are gender differences on EDT and fear of heights (LeBeau et al., 2010; Simons \& Gaher, 2005), an independent samples $t$-test was conducted to assess for gender differences. Results indicated that there were no statistically significant gender differences on the DTS, $t(80)=1.40, p=.18$; the AQ-Anxiety, $t(80)=-.98, p=.33$; or the DASS-21, $t(80)=-.54, p=.59$.

In order to test for differences between undergraduate students and community participants on the DTS, AQ-Anxiety, and DASS-21, three independent samples $t$-tests were conducted. There were no differences in DTS scores, $t(83)=-1.10, p=.28$; AQ-Anxiety scores, $t(83)=.83, p=.41$; or DASS-21 scores, $t(83)=.35, p=.73$, between the two groups.

A one-way ANOVA revealed no significant differences in DTS scores, $F(5,79)=.06, p$ $=.99 ;$ AQ-Anxiety scores, $F(5,79)=.33, p=.90$; or DASS-21 scores, $F(5,79)=.33, p=.89$, based on race.

\section{Correlations}

Pearson bivariate correlations were conducted to examine relationships between the predictors and dependent variables (see table 3 ). EDT (assessed by the DTS ${ }^{4}$ ) was negatively correlated with general negative affect (DASS-21; $r=-.45, p<.01$ ), such that individuals who reported they were unable to tolerate emotional distress experienced more general negative affect. Surprisingly, DTS was not correlated with any other variables. DASS-21 was also not correlated with any other variables.

As expected, fear of heights (AQ-Anxiety) was significantly correlated with all dependent variables in the in vivo BAT (i.e. avoidance, peak anxiety, anxious cognitions, and bodily sensations), such that individuals who reported higher fear of heights were more avoidant

\footnotetext{
${ }^{4}$ The DTS was scored according to the original publication, which involves computing the mean of the subscales and then averaging these subscale means together. Recent research suggests that the use of the DTS subscales does not provide incremental validity beyond using a total score (Rogers, Bardeen, Fergus, \& Benfer, 2018). Analyses were also conducted using a summed score of the DTS, and results did not differ.
} 
and anxious during the task. Fear of heights was also significantly correlated with all dependent variables in the VR BAT except for the number of steps completed $(r=-.16, p=.16)$. Selfreported avoidance of heights scenarios (AQ-Avoidance) was significantly correlated with all BAT outcomes (all $r \geq .33$, all $p<.05$ ). Avoidance in the VR BAT was not significantly correlated with any other outcome variables on this task except for bodily sensations in VR $(r=-$ $.22, p<.05)$, indicating that individuals who stopped sooner on the VR BAT reported more bodily sensations during the task. See table 3 for all correlations between variables.

\section{Primary analysis}

Two hierarchical regressions were conducted to determine if DTS predicted behavioral avoidance (both in VR and in vivo) above and beyond fear of heights and general negative affect (see table 4). AQ-Anxiety was entered into the first block; AQ-Anxiety and DASS-21 were entered into the second block; and AQ-Anxiety, DASS-21, and DTS were entered into the last step.

Results demonstrated that the final regression model accounted for $8.2 \%$ of the variance in avoidance in the in vivo task and was not statistically significant, $F(3,81)=2.42, p=.07$. Only AQ-Anxiety uniquely and significantly predicted avoidance in the in vivo task in the final model $(\beta=-.27, t=-2.46, p=.02)$. Neither DASS-21 $(\beta=.18, t=1.46, p=.15)$ nor DTS $(\beta=$ $.07, t=.62, p=.54)$ uniquely predicted avoidance in the in vivo task.

In the VR task, the final regression model including fear of heights, general negative affect, and emotional distress tolerance only accounted for $3.3 \%$ of variance in avoidance, $F(3$, $81)=.93, p=.43$. Neither AQ-Anxiety $(\beta=-.17, t=-1.56, p=.12)$, DASS-21 $(\beta=.10, t=.83, p$ $=.41)$, nor DTS $(\beta=.01, t=.09, p=.93)$ predicted avoidance in the VR task. 


\section{Secondary analyses}

A series of six additional hierarchical regressions were conducted to test secondary hypotheses that EDT (as assessed by DTS) would predict peak anxiety ratings, anxious cognitions, and bodily sensations during both BATs above and beyond fear of heights and general negative affect.

Results demonstrated that AQ-Anxiety, DASS-21, and DTS accounted for $16.5 \%$ of the variance in peak anxiety in the in vivo task, $F(3,81)=5.34, p=.00$ (see table 5). AQ-Anxiety $(\beta$ $=.31, t=3.01, p=.00)$ and DASS-21 $(\beta=-.26, t=-2.60, p=.03)$ were both significant predictors of peak anxiety. In the final step of the regression model, the addition of DTS accounted for an additional $6.3 \%$ in the explained variance in peak anxiety $(\beta=-.28, t=-2.48, p$ $=.02)$. However, similar results were not found in the VR task. While the regression model was significant and accounted for $9.8 \%$ of the variance in peak anxiety, $F(3,81)=2.95, p=.04$ (see table 5), only AQ-Anxiety uniquely predicted peak anxiety during the task $(\beta=.27, t=2.52, p=$ $.01)$. Results were unchanged when the number of steps completed in the BAT was entered as a covariate.

DTS did not significantly predict anxious cognitions above fear of heights or general negative affect in either of the two BATs (see table 6). In the in vivo task, the final regression model was significant and accounted for $21.1 \%$ of the explained variance, $F(3,81)=7.23, p<$ .001 , but only AQ-Anxiety uniquely predicted anxious cognitions $(\beta=.46, t=4.52, p<.001)$. DTS did not predict anxious cognitions in the in vivo task $(\beta=-.05, t=-.47, p=.64)$. Similarly, only AQ-Anxiety significantly predicted anxious cognitions in the VR task $(\beta=.39, t=3.84, p<$ $.001)$, though the full model was significant and accounted for $15.4 \%$ of the explained variance, 
$F(3,81)=6.09, p=.001$. DTS did not uniquely predict anxious cognitions in the VR task $(\beta=-$ $.04, t=-.37, p=.71)$.

Lastly, DTS did not significantly predict bodily sensations above and beyond fear of heights and general negative affect in either of the BATs (see table 7). Although the overall regression model was significant in the in vivo task and accounted for $20.6 \%$ of the explained variance in bodily sensations, $F(3,81)=7.00, p<.001$, only AQ-Anxiety predicted BSQ $(\beta=$ $.44, t=4.37, p<.001)$. DTS did not predict BSQ $(\beta=-.03, t=-.30, p=.77)$. Similar results

emerged for the VR task. Although the overall model was significant and accounted for $15.1 \%$ of explained variance in bodily sensations, $F(3,81)=4.81, p<.05$, DTS was not a unique predictor $(\beta=-.06, t=-.52, p=.60)$ whereas AQ-Anxiety uniquely contributed $(\beta=.37, t=3.54$, $p=.001)$.

\section{Post-hoc analyses}

Following planned analyses, we conducted post-hoc analyses to determine whether EDT (as assessed by DTS) significantly predicted self-reported avoidance of heights above fear of heights and general negative affect. Given that a number of studies have found that self-reported behavior is related to DTS scores (e.g. Anestis et al., 2007; Huang et al., 2009; Kozak \& Fought, 2011; Timpano et al., 2009; Williams, 2012), it was thought that DTS might better predict selfreported avoidance of heights than actual avoidance of heights. Results demonstrated that AQAnxiety, DASS-21, and DTS accounted for $63.1 \%$ of explained variance in self-reported avoidance of heights, $F(3,81)=46.20, p<.001$. In this regression model, DTS emerged as a unique predictor of self-reported avoidance behavior (see table $8 ; \beta=-.16, t=-2.14, p=.04$ ).

Given that so many participants completed all steps of the BATs, another exploratory analysis was conducted in which participants were dichotomized as either completers or non- 
completers on the tasks. An independent samples $t$-test was conducted to assess differences between completers and non-completers in the in vivo BAT. Those who did not complete all steps of the in vivo BAT compared to those who did reported significantly higher AQ-Anxiety scores, $t(83)=2.66, p=.01 ;$ ACQ scores, $t(83)=2.57, p=.01$; BSQ scores, $t(83)=2.50, p=$ .01 ; and peak anxiety during the task, $t(83)=3.97, p<.001$. There were no differences on DTS scores $(p>.05)$.

In the VR BAT, those who did not complete all of the steps compared to those who did reported significantly higher BSQ scores, $t(83)=2.84, p=.01$, and higher peak anxiety that trended towards significance, $t(83)=1.99, p=.05$. There were no differences on AQ-Anxiety, ACQ, or DTS (all $p>.05)$.

\section{Discussion}

The current study assessed the extent to which EDT predicted in-the-moment fear responding in a heights-fearful sample on two behavioral tasks above and beyond fear of heights and general negative affect. The results of this study demonstrated that EDT — as measured by the Distress Tolerance Scale (DTS; Simons \& Gaher, 2005)— did not predict behavioral avoidance, anxious cognitions, or bodily sensations in an in vivo BAT or in a VR BAT. Although EDT did predict peak anxiety during the in vivo BAT beyond fear of heights and general negative affect, these results were not replicated in the VR BAT. Post-hoc analyses revealed that EDT did, however, predict self-reported avoidance of heights above fear of heights and general negative affect.

\section{Emotional distress tolerance and peak anxiety}

Although EDT predicted peak anxiety in the in vivo task above fear of heights and general negative affect, it did not predict peak anxiety in the VR task. This may suggest that 
EDT plays a role in predicting anxiety in a task (i.e. the in vivo task) that elicited less severe anxiety, anxious cognitions, and bodily sensations (see table 2 for BAT outcomes). Given this, participants may have perceived this task to be "easier" (recall that $77.6 \%$ participants completed the in vivo task, but only $43.5 \%$ completed the VR task). However, we are hesitant to overinterpret this finding, given that EDT did not predict any other BAT outcomes.

\section{What predicts avoidance?}

The results from this study suggest that other factors besides one's perceived ability to tolerate emotional distress may more directly impact whether or not an individual exhibits avoidance behaviors when in the presence of feared stimuli. Expectedly, fear of heights significantly predicted avoidance in the in vivo BAT. In addition, anxious cognitions, bodily sensations, and peak anxiety experienced during the task were correlated with avoidance. Although fear of heights surprisingly did not predict avoidance in the VR task, results demonstrated that increased bodily sensations during the VR task were correlated with avoidance behavior, such that individuals who reported experiencing more bodily sensations discontinued the task sooner. This is in line with past research using a spider-phobic sample that showed that more bodily sensations are significantly correlated with higher peak anxiety ratings and less approach behavior during a VR BAT for spider fear (Muhlberger, Sperber, Wieser, \& Pauli, 2008).

Further, bodily sensations may have been related to avoidance in the VR BAT due to participants prematurely stopping the task due to motion sickness or due to misinterpreting bodily sensations related to motion sickness as related to their anxiety instead (or vice versa). In another study that used a similar VR setup, researchers found that over half of all participants reported some degree of motion sickness (Munafo, Diedrick, \& Stoffregen, 2017). A review of 
VR in anxiety disorders reported that this motion sickness can include symptoms such as sweating, nausea, and awareness of the stomach (Krijn, Emmelkamp, Olafsson, \& Biemond, 2004). These specific symptoms of motion sickness overlap with items on the Body Sensations Questionnaire (BSQ; Chambless et al., 1984) used in this study, potentially inflating the anxietyrelated bodily sensations that participants reported. To account for these issues, future studies that utilize VR for assessing fear responding should include measures of one's familiarity with VR, motion sickness, and how "realistic" the VR experience felt.

\section{Perceived versus actual behavior}

With the exception of EDT predicting peak anxiety in the in vivo task, a thorough discussion of why the primary and secondary hypotheses were not supported is warranted, especially given that theories of distress tolerance posit that those with poorer EDT should be less willing to stay in distressing situations (Leyro et al., 2010). First, the Distress Tolerance Scale assesses a person's perception of their ability to tolerate distress, rather than their actual ability to tolerate distress (Simons \& Gaher, 2005). Research demonstrating that self-reported attitudes do not always predict behavior (Gross \& Niman, 1975; Kraus, 1995) may explain why scores on a self-report EDT measure did not significantly predict real-life avoidance behaviors on the two heights BATs. It may be the case that although many people report that they perceive the feeling of distress to be intolerable and unpleasant, they often still endure this experience and underestimate their actual ability to handle it simply because they find the experience so aversive.

Interestingly, although EDT did not predict actual behavior on the two heights BATs, post-hoc analyses revealed that EDT did account for additional variance above and beyond fear of heights and general negative affect on a measure of self-reported avoidance of heights. On this 
self-report measure, participants were asked to rate whether or not they would avoid a certain heights situation such as riding a Ferris wheel or standing next to an open window on a high floor of a building (AQ-Avoidance; Cohen, 1977). Given that participants were not actually asked to complete these tasks and may have never been in these types of situations before, their responses on this questionnaire are a reflection of their perception of their avoidance of heights scenarios rather than their actual avoidance. Thus, post-hoc analyses suggest that someone's perceived ability to tolerate emotional distress predicts their perceived avoidance of heights, but does not predict their actual avoidance of heights.

Relatedly, a meta-analysis on attitude-behavior studies (Kraus, 1995) found that attitudes and behaviors are only moderately correlated, indicating that there are other factors besides one's beliefs that contribute to behavior. Importantly, this meta-analysis (Kraus, 1995) found that attitude-behavior correlations were stronger in studies utilizing self-report measures of behavior rather than actual, observable behavior. This is similar to results from the current study; while the perceived ability to handle emotional distress did not predict actual behavior, it did predict self-reported behavior.

The results from these post-hoc analyses are in line with previous research on EDT that found that the DTS is related to self-reported behaviors such as dysregulated eating, worrying, hoarding, and compulsive buying (Anestis et al., 2007; Huang et al., 2009; Kozak \& Fought, 2011; Timpano et al., 2009; Williams, 2012). These behaviors and avoidance of heights scenarios are related in that they all function to reduce the experience of negative affect and are negatively reinforcing. The relationship between DTS and self-reports of behavior appears to be a robust finding. Importantly, these studies only utilized self-report measures and did not include behavioral measures assessing how people actually react. In this study, self-reported avoidance 
of heights was not related to avoidance in the VR BAT and was only weakly correlated with avoidance in the in vivo BAT. Taken together, this suggests that individuals may not be accurate reporters of their own behavior and this may partially explain why EDT did not predict behavior.

\section{Clinical implications}

The findings from this study have important clinical implications for cognitive-behavioral therapy for anxiety. Someone who feels that the experience of anxiety is unbearable and overwhelming may be unwilling to participate in anxiety-inducing treatment (such as exposures) and may instead continue to engage in negatively-reinforcing avoidance behaviors. However, given that someone's self-reported ability to tolerate emotional distress did not predict their actual behavior in this study, this suggests that those who experience anxiety may underestimate their ability to stay in anxiety-provoking situations. In other words, just because a patient says they that they do not think they will be able to engage in exposures does not mean that this will actually be the case, and they may find that they do better than they expect.

Further, although EDT was not related to behavior, it may still be important to other psychological processes occurring during distressing situations, such as one's interpretation of the situation or their judgment of their own emotional reaction. The ability to tolerate emotional distress is an important skill often taught in therapy to help patients better manage their symptoms (e.g. Dialectical Behavior Therapy; Linehan, 1993). Being able to handle negative emotions (such as anxiety) is also important during exposures, as patients will be asked to directly confront something that makes them anxious and to stay in the situation until they habituate. Given this and the fact that EDT was related to one's general negative affect, results from this study suggest that EDT may still be a helpful target for intervention (despite EDT not 
predicting behavior). It will be important for future studies to identify whether there is a causal relationship between emotional distress tolerance and general negative affect.

\section{Strengths and limitations}

There are limitations to consider when interpreting the current study's findings. First, the majority of participants in the in vivo BAT (77.6\%) and nearly half of participants in the VR BAT $(43.5 \%)$ completed all of the steps of the behavioral tasks, indicating that the BATs may have been too easy. Consequently, the sample had limited variability which reduces the ability to see possible relationships between DTS and avoidance. However, despite these ceiling effects for approach behavior, one notable strength from this study was the use of multiple BATs for fear of heights, increasing the ecological validity of these findings.

Since the majority of participants were undergraduates and since the in vivo BAT took place in a common building on campus, it is possible that some participants may have had exposure to this stimulus prior to completing the study. Further, many people are required to climb stairs in their daily lives and some may have already habituated to staircases in general. Given the heterogeneity of types of heights individuals may fear (for examples, see Cohen, 1977), it is also likely that some participants were simply not afraid of stairs. In the VR task, some participants may have felt like the task was not realistic enough. Excitement or interest in using a VR system may have also contributed to some participants' willingness to continue the task despite their distress. Lastly, experimenters noted that multiple participants appeared to cope with their distress by reassuring themselves that the height was not real during the VR BAT (though this information was not systematically collected). Thus, future studies on EDT in phobic samples should include BATs that are more challenging, have more steps, and use stimuli that participants are less likely to have already habituated. It may also prove helpful to adopt an 
idiographic approach to selecting BAT stimuli that taps into a participant's unique fears related to heights.

Another limitation of this study was the use of a non-clinical sample. Although all participants reported high fear of heights, it is unknown what proportion of the sample met diagnostic criteria for specific phobia of heights since participants were not assessed by a clinician. Since assessment of heights-fear was limited to using self-reported symptoms (and did not include diagnostic interviews), the results from this study may not be generalizable to clinical populations.

Lastly, the sample used in the current study was mostly white, female, and college-aged, further limiting the generalizability of these findings. Further, the study consisted primarily of college students, and although recruitment was open to the community and there was a wide age range of participants (18 to 62 years old), the mean age was only 22.69 years old. Future studies would benefit from recruiting participants with a wider distribution of ages, using a more racially diverse sample, and having a more even distribution of male and female participants.

\section{Future directions}

Although BATs are theoretically designed to objectively assess an individual's avoidance behavior, they are artificial (i.e. participants know they are part of a research study and that they are being observed) and thus may not fully capture the behavior that would occur in a more naturalistic setting. It is possible that certain demand characteristics contributed to participants' behavior in such a way that participants pushed themselves to go further on the BATs than they normally would in their day-to-day lives. For example, while a participant in their typical environment may avoid heights scenarios due to their fear of falling and their perception that they will not be able to handle the distress, the presence of a research assistant and the 
knowledge that they were being assessed on how far they went up the staircase may have served as a motivator for participants. Given this, simulated exposures to feared stimuli in a lab environment may not adequately capture real-life behavior. Future studies may better capture typical behavior by utilizing ecological momentary assessment methodology that asks participants throughout the day how many times they avoided heights (or other stimuli).

Since the DTS includes items related to one's judgment of the experience of distress (Veilleux et al., 2019), it may be helpful to identify for any given patient whether the more "important" aspect of EDT for them personally is their willingness to continue engaging in treatment despite their distress (i.e. the behavioral component), or their judgments of their experience (i.e. the cognitive component). Given this study's finding that the DTS did not predict actual avoidance behavior, it may be the case that poor self-reported EDT more strongly influences distress-related cognitions rather than behaviors for some individuals. If this is the case, poorer EDT may cause an anxiety-provoking situation to feel overwhelming and intolerable, indirectly contributing to avoidance behaviors. Future studies should further examine this cognitive component of EDT to determine what role someone's judgment of their distress plays into their experience of distress. Determining which factors play a role in the relationship between perceived EDT and behavior may help better elucidate why people behave differently when confronted with things they fear.

\section{Summary}

In summary, the present study demonstrated that one's perceived ability to handle emotional distress does not predict the majority of assessed in-the-moment fear responses when confronted with a feared stimulus. While EDT did not predict actual avoidance in a heights BAT, it did predict one's self-reported avoidance of heights scenarios. The finding that EDT predicted 
self-reported behaviors is in line with past research in the distress tolerance literature on the relationship between the DTS and negatively-reinforcing behaviors. Given findings from attitude-behavior studies, it may be the case that what people think they will do does not map onto what they actually do. Although one's perceived ability to tolerate emotional distress likely taps into important psychological processes (such as their interpretation of a distressing scenario or their judgment of their emotional reaction), the results of this study suggest that it may not adequately account for how people actually behave in the presence of distressing stimuli. 


\section{References}

Abrantes, A. M., Strong, D. R., Lejuez, C. W., Kahler, C. W., Carpenter, L. L., Price, L. H., ... \& Brown, R. A. (2008). The role of negative affect in risk for early lapse among low distress tolerance smokers. Addictive behaviors, 33(11), 1394-1401.

American Psychiatric Association (2013). Diagnostic and statistical manual of mental disorders (5th ed.). Washington, DC: American Psychiatric Association Publishing.

Anestis, M. D., Selby, E. A., Fink, E. L., \& Joiner, T. E. (2007). The multifaceted role of distress tolerance in dysregulated eating behaviors. International Journal of Eating Disorders, 40(8), 718-726.

Antony, M. M., Bieling, P. J., Cox, B. J., Enns, M. W., \& Swinson, R. P. (1998). Psychometric properties of the 42-item and 21-item versions of the Depression Anxiety Stress Scales in clinical groups and a community sample. Psychological assessment, 10(2), 176.

Baker, B. L., Cohen, D. C., \& Saunders, J. T. (1973). Self-directed desensitization for acrophobia. Behaviour Research and Therapy, 11(1), 79-89.

Barlow, D.H. (2002). Anxiety and its disorders: The nature and treatment of anxiety and panic (2nd ed.). New York: Guilford.

Bernstein, A., Zvolensky, M. J., Vujanovic, A. A., \& Moos, R. (2009). Integrating anxiety sensitivity, distress tolerance, and discomfort intolerance: A hierarchical model of affect sensitivity and tolerance. Behavior Therapy, 40(3), 291-301.

Bourque, P., \& Ladouceur, R. (1980). An investigation of various performance-based treatments with acrophobics. Behaviour Research and Therapy, 18(3), 161-170.

Brown, R. A., Lejuez, C. W., Kahler, C. W., \& Strong, D. R. (2002). Distress tolerance and duration of past smoking cessation attempts. Journal of abnormal psychology, 111(1), 180. 
Brown, R. A., Lejuez, C. W., Strong, D. R., Kahler, C. W., Zvolensky, M. J., Carpenter, L. L., ... \& Price, L. H. (2009). A prospective examination of distress tolerance and early smoking lapse in adult self-quitters. Nicotine \& Tobacco Research, 11(5), 493-502.

Chambless, D. L., Caputo, G. C., Bright, P., \& Gallagher, R. (1984). Assessment of fear of fear in agoraphobics: the body sensations questionnaire and the agoraphobic cognitions questionnaire. Journal of consulting and clinical psychology, 52(6), 1090.

Cohen, D. C. (1977). Comparison of self-report and overt-behavioral procedures for assessing acrophobia. Behavior Therapy, 8(1), 17-23.

Cohen, D. C. (1972). Personality predictors and the outcome of varieties of desensitization. Unpublished doctoral dissertation, Harvard University, Cambridge, MA.

Compton, P., Charuvastra, V. C., \& Ling, W. (2001). Pain intolerance in opioid-maintained former opiate addicts: effect of long-acting maintenance agent. Drug and alcohol dependence, 63(2), 139-146.

Cougle, J. R., Timpano, K. R., Fitch, K. E., \& Hawkins, K. A. (2011). Distress tolerance and obsessions: an integrative analysis. Depression and anxiety, 28(10), 906-914.

Craske, M. G., Rapee, R. M., \& Barlow, D. H. (1988). The significance of panic-expectancy for individual patterns of avoidance. Behavior Therapy, 19(4), 577-592.

Deacon, B., \& Olatunji, B. O. (2007). Specificity of disgust sensitivity in the prediction of behavioral avoidance in contamination fear. Behaviour research and therapy, 45(9), 2110-2120.

Emmelkamp, P. M. G., Krijn, M., Hulsbosch, A. M., De Vries, S., Schuemie, M. J., \& Van der Mast, C. A. P. G. (2002). Virtual reality treatment versus exposure in vivo: a comparative evaluation in acrophobia. Behaviour research and therapy, 40(5), 509-516. 
Glassman, L. H., Martin, L. M., Bradley, L. E., Ibrahim, A., Goldstein, S. P., Forman, E. M., \& Herbert, J. D. (2016). A brief report on the assessment of distress tolerance: Are we measuring the same construct?. Journal of Rational-Emotive \& Cognitive-Behavior Therapy, 34(2), 87-99.

Gross, S. J., \& Niman, C. M. (1975). Attitude-behavior consistency: A review. Public opinion quarterly, 39(3), 358-368.

Hodgson, R., \& Rachman, S. (1974). II. Desynchrony in measures of fear. Behaviour Research and Therapy, 12(4), 319-326.

Huang, K., Szabó, M., \& Han, J. (2009). The relationship of low distress tolerance to excessive worrying and cognitive avoidance. Behaviour Change, 26(4), 223-234.

Keough, M. E., Riccardi, C. J., Timpano, K. R., Mitchell, M. A., \& Schmidt, N. B. (2010). Anxiety symptomatology: The association with distress tolerance and anxiety sensitivity. Behavior Therapy, 41(4), 567-574.

Kozak, A. T., \& Fought, A. (2011). Beyond alcohol and drug addiction. Does the negative trait of low distress tolerance have an association with overeating?. Appetite, 57(3), 578-581.

Kraus, S. J. (1995). Attitudes and the prediction of behavior: A meta-analysis of the empirical literature. Personality and social psychology bulletin, 21(1), 58-75.

Krijn, M., Emmelkamp, P. M., Olafsson, R. P., \& Biemond, R. (2004). Virtual reality exposure therapy of anxiety disorders: A review. Clinical psychology review, 24(3), 259-281.

Krypotos, A. M., Effting, M., Kindt, M., \& Beckers, T. (2015). Avoidance learning: a review of theoretical models and recent developments. Frontiers in Behavioral Neuroscience, 9, 189. 
Lang, P. J. (1978). Language, imagery, and emotion. In P. Pliner, K. R. Blankstein and I. M. Spigel (Eds.). Advances in study of emotion and affect, Vol. 5: Perceptions of emotion in self and others (pp. 107-117). New York and London: Plenum.

Lang, P. J., Cuthbert, B. N., \& Bradley, M. M. (1998). Measuring emotion in therapy: Imagery, activation, and feeling. Behavior Therapy, 29(4), 655-674.

Lang, P. J., \& Lazovik, A. D. (1963). Experimental desensitization of phobia. The Journal of Abnormal and Social Psychology, 66(6), 519.

LeBeau, R. T., Glenn, D., Liao, B., Wittchen, H. U., Beesdo-Baum, K., Ollendick, T., \& Craske, M. G. (2010). Specific phobia: a review of DSM-IV specific phobia and preliminary recommendations for DSM-V. Depression and Anxiety, 27(2), 148-167.

Lejuez, C. W., Kahler, C. W., \& Brown, R. A. (2003). A modified computer version of the Paced Auditory Serial Addition Task (PASAT) as a laboratory-based stressor. The Behavior Therapist.

Leyro, T. M., Bernstein, A., Vujanovic, A. A., McLeish, A. C., \& Zvolensky, M. J. (2011). Distress Tolerance Scale: A confirmatory factor analysis among daily cigarette smokers. Journal of psychopathology and behavioral assessment, 33(1), 47-57.

Leyro, T. M., Zvolensky, M. J., \& Bernstein, A. (2010). Distress tolerance and psychopathological symptoms and disorders: a review of the empirical literature among adults. Psychological bulletin, 136(4), 576.

Linehan, M. M. (1993). Skills training manual for treating borderline personality disorder. Guilford Press.

Lovibond, S. H., \& Lovibond, P. F. (1995). Manual for the depression anxiety stress scales. Sydney: Psychology Foundation. 
McGlynn, F.D. (1988). Behavioral avoidance tests. In Hersen M., and Bellack A. (eds): Dictionary of behavioral assessment techniques. Oxford: Pergamon Press, 1988.

McHugh, R. K., Daughters, S. B., Lejuez, C. W., Murray, H. W., Hearon, B. A., Gorka, S. M., \& Otto, M. W. (2011). Shared variance among self-report and behavioral measures of distress intolerance. Cognitive therapy and research, 35(3), 266-275.

Mowrer, O. (1953). Psychotherapy: theory and research. New York, NY: Ronald Press.

Mühlberger, A., Sperber, M., Wieser, M. J., \& Pauli, P. (2008). A virtual reality behavior avoidance test (VR-BAT) for the assessment of spider phobia. Journal of CyberTherapy and Rehabilitation, 1(2), 147-158.

Munafo, J., Diedrick, M., \& Stoffregen, T. A. (2017). The virtual reality head-mounted display Oculus Rift induces motion sickness and is sexist in its effects. Experimental brain research, 235(3), 889-901.

Perkins, K. A., Karelitz, J. L., Giedgowd, G. E., Conklin, C. A., \& Sayette, M. A. (2010). Differences in negative mood-induced smoking reinforcement due to distress tolerance, anxiety sensitivity, and depression history. Psychopharmacology, 210(1), 25-34.

Rachman, S. (1976). The passing of the two-stage theory of fear and avoidance: Fresh possibilities. Behaviour Research and Therapy, 14(2), 125-131.

Rachman, S., \& Hodgson, R. (1974). I. Synchrony and desynchrony in fear and avoidance. Behaviour Research and therapy, 12(4), 311-318.

Rogers, T. A., Bardeen, J. R., Fergus, T. A., \& Benfer, N. (2018). Factor Structure and Incremental Utility of the Distress Tolerance Scale: A Bifactor Analysis. Assessment, doi: 1073191118789496. 
Simons, J. S., \& Gaher, R. M. (2005). The Distress Tolerance Scale: Development and validation of a self-report measure. Motivation and Emotion, 29(2), 83-102.

Sinclair, S. J., Siefert, C. J., Slavin-Mulford, J. M., Stein, M. B., Renna, M., \& Blais, M. A. (2012). Psychometric evaluation and normative data for the depression, anxiety, and stress scales-21 (DASS-21) in a nonclinical sample of US adults. Evaluation \& the Health Professions, 35(3), 259-279.

Steinman, S. A., \& Teachman, B. A. (2011). Cognitive processing and acrophobia: validating the Heights Interpretation Questionnaire. Journal of anxiety disorders, 25(7), 896-902.

Steketee, G., Chambless, D. L., Tran, G. Q., Worden, H., \& Gillis, M. M. (1996). Behavioral avoidance test for obsessive compulsive disorder. Behaviour Research and Therapy, 34(1), 73-83.

Strong, D. R., Lejuez, C. W., Daughters, S., Marinello, M., Kahler, C. W., \& Brown, R. A. (2003). The computerized mirror tracing task, version 1. Unpublished manual.

Timpano, K. R., Buckner, J. D., Richey, J. A., Murphy, D. L., \& Schmidt, N. B. (2009). Exploration of anxiety sensitivity and distress tolerance as vulnerability factors for hoarding behaviors. Depression and anxiety, 26(4), 343-353.

Trafton, J. A., \& Gifford, E. V. (2011). Biological bases of distress tolerance. In M. J. Zvolensky, A. Bernstein, \& A. A. Vujanovic (Eds.), Distress tolerance (pp. 80-103). New York, NY: The Guilford Press.

Trujillo, M. A., Khoddam, R., Greenberg, J. B., Dyal, S. R., Ameringer, K. J., Zvolensky, M. J., \& Leventhal, A. M. (2017). Distress tolerance as a correlate of tobacco dependence and motivation: Incremental relations over and above anxiety and depressive symptoms. Behavioral Medicine, 43(2), 120-128. 
Veilleux, J. C., Pollert, G. A., Zielinski, M. J., Shaver, J. A., \& Hill, M. A. (2019). Behavioral assessment of the negative emotion aspect of distress tolerance: Tolerance to emotional images. Assessment, 26(3), 386-403.

Williams, A. D. (2012). Distress tolerance and experiential avoidance in compulsive acquisition behaviours. Australian Journal of Psychology, 64(4), 217-224.

Zvolensky, M. J., Feldner, M. T., Eifert, G. H., \& Brown, R. A. (2001). Affective style among smokers: Understanding anxiety sensitivity, emotional reactivity, and distress tolerance using biological challenge. Addictive behaviors, 26(6), 901-915.

Zvolensky, M. J., Marshall, E. C., Johnson, K., Hogan, J., Bernstein, A., \& Bonn-Miller, M. O. (2009). Relations between anxiety sensitivity, distress tolerance, and fear reactivity to bodily sensations to coping and conformity marijuana use motives among young adult marijuana users. Experimental and clinical psychopharmacology, 17(1), 31.

Zvolensky, M. J., Vujanovic, A. A., Bernstein, A., \& Leyro, T. (2010). Distress tolerance: Theory, measurement, and relations to psychopathology. Current Directions in Psychological Science, 19(6), 406-410. 


\section{Tables and Figures}

Table 1. Demographic data.

\begin{tabular}{llcc}
\hline & & $N$ & $\%$ \\
\hline Gender & Males & 19 & 22.4 \\
& Females & 63 & 74.1 \\
\multirow{5}{*}{ Race/ethnicity } & Other & 3 & 3.5 \\
& White & 57 & 67.1 \\
& Hispanic & 3 & 3.5 \\
& Black & 8 & 9.4 \\
& Asian & 10 & 11.8 \\
& Other & 2 & 2.4 \\
\multirow{5}{*}{ Student Status } & 5 & 5.9 \\
& 2 or more races & 66 & 77.6 \\
& Undergraduate student & 19 & 22.4 \\
\hline
\end{tabular}

Table 2. Descriptive data on BAT outcomes.

\begin{tabular}{llcc}
\hline BAT Type & \multicolumn{1}{c}{ BAT Outcome } & $M$ & $S D$ \\
\hline in vivo & Number of steps completed & 7.38 & 1.31 \\
& Peak anxiety & 59.35 & 23.98 \\
& ACQ $^{*}$ & 19.33 & 11.36 \\
VR & BSQ & 22.27 & 25.22 \\
& Number of steps completed & 6.09 & 2.16 \\
& Peak anxiety & 71.26 & 23.54 \\
& ACQ & 25.22 & 12.51 \\
& BSQ & 28.15 & 14.97 \\
\hline
\end{tabular}

*For comparison, this is the non-transformed variable's mean and standard deviation. 
Table 3. Bivariate correlations between predictor and dependent variables.

\begin{tabular}{|c|c|c|c|c|c|c|c|c|c|c|c|c|c|c|}
\hline & \multicolumn{14}{|c|}{ Correlation Coefficients } \\
\hline & 1 & 2 & 3 & 4 & 5 & 6 & 7 & 8 & 9 & 10 & 11 & 12 & 13 & 14 \\
\hline 1. DTS & 1 & & & & & & & & & & & & & \\
\hline 2. AQ- Anxiety & -.11 & 1 & & & & & & & & & & & & \\
\hline 3. AQ- Avoidance & -.17 & $.78 * *$ & 1 & & & & & & & & & & & \\
\hline 4. DASS-21 total & $-.45^{* *}$ & .20 & .07 & 1 & & & & & & & & & & \\
\hline 5. DASS-21 transformed & $-.45^{* *}$ & .19 & .05 & $.98 * *$ & 1 & & & & & & & & & \\
\hline 6. Stop point in vivo & .02 & $-.24 *$ & $-.31 * *$ & .04 & .09 & 1 & & & & & & & & \\
\hline 7. Peak anxiety in vivo & -.20 & $.29 * *$ & $.38 * *$ & -.06 & -.07 & $-.40 * *$ & 1 & & & & & & & \\
\hline 8. ACQ in vivo & -.08 & $.44^{* *}$ & $.52 * *$ & .11 & .10 & $-.22 *$ & $.52 * *$ & 1 & & & & & & \\
\hline 9. ACQ in vivo transformed & -.09 & $.46^{* *}$ & $.52 * *$ & .10 & .10 & $-.24 *$ & $.56^{* *}$ & $.97 * *$ & 1 & & & & & \\
\hline 10. BSQ in vivo & -.09 & $.45^{* *}$ & $.47 * *$ & .14 & .13 & $-.26^{*}$ & $.53 * *$ & $.82 * *$ & $.80 * *$ & 1 & & & & \\
\hline 11. Stop point in VR & -.02 & -.16 & $-.29 * *$ & .06 & .07 & $.34 * *$ & -.21 & -.11 & -.09 & -.16 & 1 & & & \\
\hline 12. Peak anxiety in VR & -.13 & $.29 * *$ & $.26^{*}$ & .10 & .15 & -.05 & $.55 * *$ & $.39 * *$ & $.43 * *$ & $.43 * *$ & -.11 & 1 & & \\
\hline 13. ACQ in VR & -.12 & $.41 * *$ & $.35^{* *}$ & .17 & .18 & -.02 & $.26^{*}$ & $.68 * *$ & $.62 * *$ & $.62 * *$ & -.16 & $.54 * *$ & 1 & \\
\hline 14. BSQ in VR & -.11 & $.38^{* *}$ & $.33^{* *}$ & .13 & .13 & -.09 & $.24^{*}$ & $.56^{* *}$ & $.52 * *$ & $.74 * *$ & $-.22 *$ & $.50^{* *}$ & $.82 * *$ & 1 \\
\hline
\end{tabular}

Note. $* * p<0.01 ; * p<0.05$. DTS = Distress Tolerance Scale; AQ = Acrophobia Questionnaire; DASS-21 = Depression Anxiety Stress Scale; $\mathrm{ACQ}=$ Agoraphobia Cognitions Questionnaires; BSQ = Body Sensations Questionnaire. 
Table 4. Hierarchical regressions of primary analyses using DTS to predict avoidance above AQAnxiety and DASS-21.

\section{B $\quad$ SE B $\quad \boldsymbol{\beta}$}

Avoidance on BAT in vivo

\begin{tabular}{rrrr}
\hline Step $1\left(\mathrm{R}^{2}=.06\right)$ & & & \\
AQ-Anxiety & -.02 & .01 & $-.24^{*}$ \\
Step 2 $\left(\Delta \mathrm{R}^{2}=.02\right)$ & & & \\
AQ-Anxiety & -.02 & .01 & $-.27^{*}$ \\
DASS-21 & .14 & .10 & .14
\end{tabular}

$\underline{\text { Step } 3}\left(\Delta \mathrm{R}^{2}=.00\right)$

$\begin{array}{llll}\text { AQ-Anxiety } & -.02 & .01 & -.27^{*}\end{array}$

$\begin{array}{llll}\text { DASS-21 } & .17 \quad .12 & .18\end{array}$

$\begin{array}{llll}\text { DTS } & .12 & .19 & .07\end{array}$

\section{Avoidance on BAT in VR}

$\underline{\text { Step } 1}\left(\mathrm{R}^{2}=.02\right)$

$\begin{array}{llll}\text { AQ-Anxiety } \quad-.02 \quad .02 & -.16\end{array}$

$\underline{\text { Step } 2}\left(\Delta \mathrm{R}^{2}=.01\right)$

$\begin{array}{cccc}\text { AQ-Anxiety } & -.02 & .02 & -.17 \\ \text { DASS-21 } & .16 & .18 & .10\end{array}$

$\underline{\text { Step } 3}\left(\Delta \mathrm{R}^{2}=.00\right)$

$\begin{array}{cccc}\text { AQ-Anxiety } & -.02 & .02 & -.17 \\ \text { DASS-21 } & .17 & .20 & .10 \\ \text { DTS } & .03 & .33 & .01\end{array}$

Note. $* * p<0.01 ; * p<0.05$. AQ-Anxiety $=$ Acrophobia Questionnaire Anxiety Subscale; DASS-21 = Depression Anxiety Stress Scale; DTS = Distress Tolerance Scale. 
Table 5. Hierarchical regressions of secondary analysis using DTS to predict peak anxiety above AQ-Anxiety and DASS-21.

\section{B SE B $\quad \boldsymbol{\beta}$}

\section{Peak anxiety in vivo}

$\begin{array}{rllll}\underline{\text { Step } 1}\left(\mathrm{R}^{2}=.09\right) & & & & \\ \text { AQ-Anxiety } & .45 & .16 & .29 * *\end{array}$

Step $2\left(\Delta \mathrm{R}^{2}=.02\right)$

$\begin{array}{llll}\text { AQ-Anxiety } & .49 & .17 & .32 * * \\ \text { DASS-21 } & -2.37 & 1.88 & -.13\end{array}$

$\underline{\text { Step } 3}\left(\Delta \mathrm{R}^{2}=.06\right)$

$\begin{array}{llll}\text { AQ-Anxiety } & .48 & .16 & .31^{* *}\end{array}$

$\begin{array}{llll}\text { DASS-21 } & -4.60 & 2.04 & -.26^{*}\end{array}$

DTS $\quad-8.29 \quad 3.35 \quad-.28^{*}$

Peak anxiety in VR

$\underline{\text { Step } 1}\left(\mathrm{R}^{2}=.09\right)$

$\begin{array}{llll}\text { AQ-Anxiety } \quad .45 \quad .16 & .29 *\end{array}$

$\underline{\text { Step } 2}\left(\Delta \mathrm{R}^{2}=.01\right)$

$\begin{array}{lrrr}\text { AQ-Anxiety } & .42 & .16 & .27 * \\ \text { DASS-21 } & 1.69 & 1.86 & .10\end{array}$

$\underline{\text { Step } 3}\left(\Delta \mathrm{R}^{2}=.01\right)$

$\begin{array}{cccc}\text { AQ-Anxiety } & .41 & .16 & .27 * \\ \text { DASS-21 } & 1.11 & 2.08 & .06 \\ \text { DTS } & -2.18 & 3.42 & -.08\end{array}$

Note. $* * p<0.01 ; * p<0.05$. AQ-Anxiety $=$ Acrophobia Questionnaire Anxiety Subscale; DASS-21 = Depression Anxiety Stress Scale; DTS = Distress Tolerance Scale. 
Table 6. Hierarchical regressions of secondary analysis using DTS to predict ACQ above AQAnxiety and DASS-21.

\section{B $\quad$ SE B $\quad \boldsymbol{\beta}$}

\section{ACQ in vivo}

$\begin{array}{rllll}\underline{\text { Step } 1}\left(\mathrm{R}^{2}=.21\right) & & & & \\ \text { AQ-Anxiety } & .04 & .01 & .46^{* *}\end{array}$

Step $2\left(\Delta \mathrm{R}^{2}=.00\right)$

$\begin{array}{llll}\text { AQ-Anxiety } & .04 & .01 & .46^{* *} \\ \text { DASS-21 } & .01 & .10 & .01\end{array}$

$\underline{\text { Step } 3}\left(\Delta \mathrm{R}^{2}=.00\right)$

$\begin{array}{llll}\text { AQ-Anxiety } & .04 & .01 & .46^{* *}\end{array}$

DASS-21 $\quad-.01 \quad .11 \quad-.02$

$\begin{array}{llll}\text { DTS } & -.08 \quad .18 & -.05\end{array}$

\section{$A C Q$ in VR}

$\underline{\text { Step } 1}\left(\mathrm{R}^{2}=.18\right)$

AQ-Anxiety $\quad .34 \quad .08 \quad .41^{* *}$

$\underline{\text { Step } 2}\left(\Delta \mathrm{R}^{2}=.01\right)$

$\begin{array}{llll}\text { AQ-Anxiety } & .32 & .08 & .39 * * \\ \text { DASS-21 } & .99 & .94 & .11\end{array}$

$\underline{\text { Step } 3}\left(\Delta \mathrm{R}^{2}=.00\right)$

$\begin{array}{cccc}\text { AQ-Anxiety } & .32 & .08 & .39 * * \\ \text { DASS-21 } & .82 & 1.05 & .09 \\ \text { DTS } & -.64 & 1.73 & -.04\end{array}$

Note. $* * p<0.01 ; * p<0.05$. AQ-Anxiety $=$ Acrophobia Questionnaire Anxiety Subscale; DASS-21 = Depression Anxiety Stress Scale; DTS = Distress Tolerance Scale; ACQ = Agoraphobic Cognitions Questionnaire. 
Table 7. Hierarchical regressions of secondary analysis using DTS to predict BSQ above AQAnxiety and DASS-21.

\section{B $\quad$ SE B $\quad \boldsymbol{\beta}$}

\section{BSQ in vivo}

$\underline{\text { Step } 1}\left(\mathrm{R}^{2}=.21\right)$

AQ-Anxiety

$.39 \quad .09 \quad .45^{* *}$

$\underline{\text { Step } 2}\left(\Delta \mathrm{R}^{2}=.00\right)$

$\begin{array}{llll}\text { AQ-Anxiety } & .38 & .09 & .44 * * \\ \text { DASS-21 } & .47 & .99 & .05\end{array}$

$\underline{\text { Step } 3}\left(\Delta R^{2}=.00\right)$

$\begin{array}{llll}\text { AQ-Anxiety } & .38 & .09 & .44 * *\end{array}$

$\begin{array}{llll}\text { DASS-21 } & .33 & 1.11 & .03\end{array}$

DTS $\quad-.54 \quad 1.83 \quad-.03$

\section{BSQ in VR}

$\underline{\text { Step } 1}\left(\mathrm{R}^{2}=.15\right)$

$\begin{array}{llll}\text { AQ-Anxiety } \quad .37 \quad .10 & .38 * *\end{array}$

$\underline{\text { Step } 2}\left(\Delta \mathrm{R}^{2}=.00\right)$

$\begin{array}{llll}\text { AQ-Anxiety } & .36 & .10 & .37 * * \\ \text { DASS-21 } & .62 & 1.15 & .06\end{array}$

$\underline{\text { Step } 3}\left(\Delta \mathrm{R}^{2}=.00\right)$

$\begin{array}{cccc}\text { AQ-Anxiety } & .36 & .10 & .37 * * \\ \text { DASS-21 } & .32 & 1.28 & .03 \\ \text { DTS } & -1.10 & 2.11 & -.06\end{array}$

Note. ${ }^{*} p<0.01 ; * p<0.05$. AQ-Anxiety $=$ Acrophobia Questionnaire Anxiety Subscale; DASS-21 = Depression Anxiety Stress Scale; DTS = Distress Tolerance Scale; BSQ = Body Sensations Questionnaire. 
Table 8. Hierarchical regression of post-hoc analysis using DTS to predict self-reported avoidance of heights (AQ-Avoidance) above AQ-Anxiety and DASS-21.

\section{B SE B $\quad \boldsymbol{\beta}$}

\section{AQ-Avoidance}

$\underline{\text { Step } 1}\left(\mathrm{R}^{2}=.60\right)$

AQ-Anxiety

$.30 \quad .03 \quad .78^{* *}$

$\underline{\text { Step } 2}\left(\Delta R^{2}=.01\right)$

$\begin{array}{cccc}\text { AQ-Anxiety } & .31 & .03 & .79 * * \\ \text { DASS-21 } & -.42 & .31 & -.10\end{array}$

$\underline{\text { Step } 3}\left(\Delta \mathrm{R}^{2}=.02\right)$

$\begin{array}{cccc}\text { AQ-Anxiety } & .30 & .03 & .79 * * \\ \text { DASS-21 } & -.74 & .34 & -.17^{*} \\ \text { DTS } & -- & .55 & -.16^{*}\end{array}$

\subsection{8}

Note. ${ }^{*} p<0.01 ; * p<0.05$. AQ-Anxiety = Acrophobia Questionnaire Anxiety Subscale; DASS-21 = Depression Anxiety Stress Scale; DTS = Distress Tolerance Scale; BSQ = Body Sensations Questionnaire. 
Figure 1: Photographs of in vivo BAT
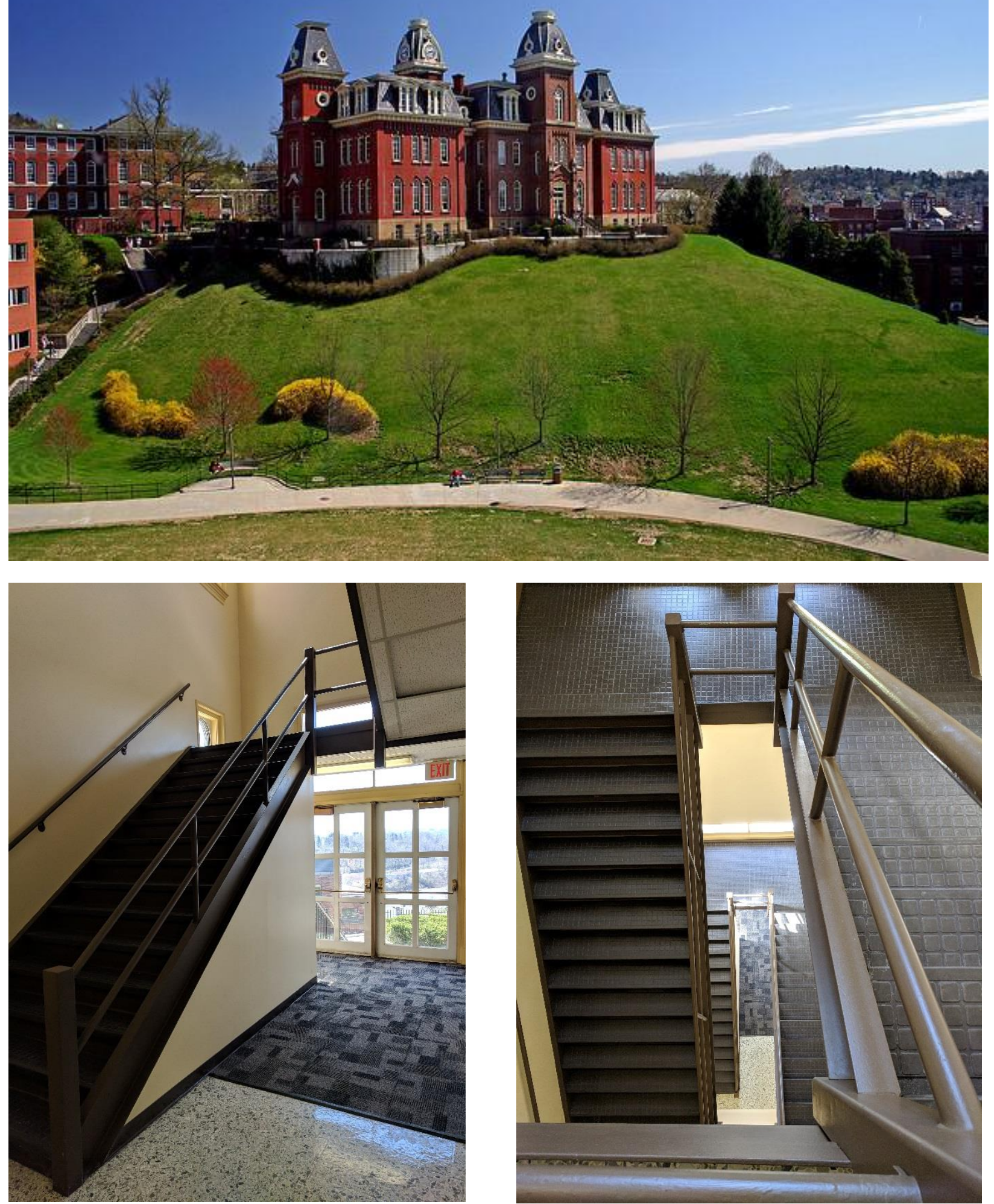
Figure 2: Photographs of VR BAT
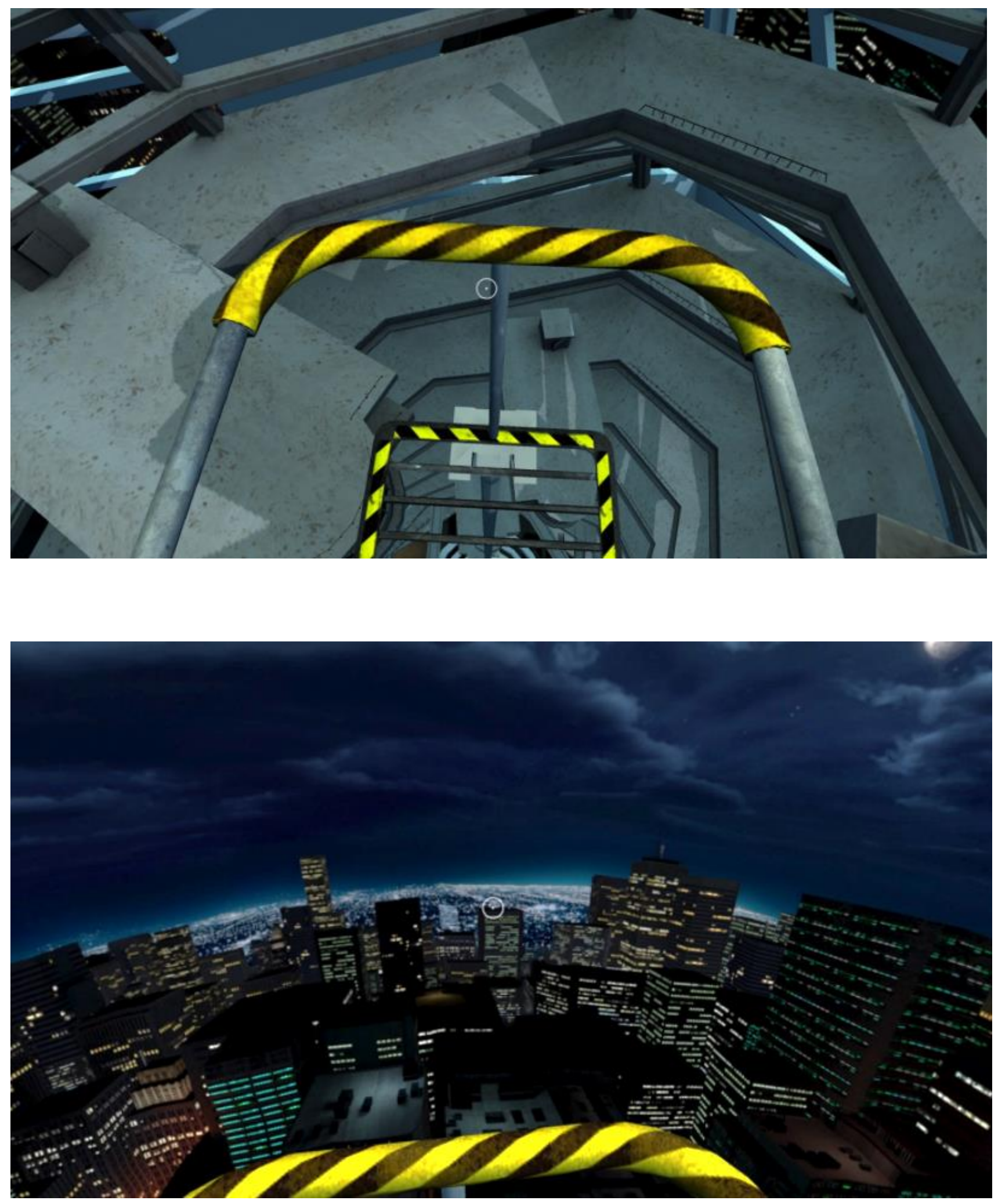